\title{
Altered Nrf2/Keap1-Bach1 equilibrium in pulmonary emphysema
}

\author{
D Goven, ${ }^{1}$ A Boutten, ${ }^{1,2}$ V Leçon-Malas, ${ }^{2}$ J Marchal-Sommé, ${ }^{1}$ N Amara, ${ }^{1}$ B Crestani, ${ }^{1,3}$ \\ M Fournier, ${ }^{4} \mathrm{G}$ Lesèche, ${ }^{5} \mathrm{P}$ Soler, ${ }^{1} \mathrm{~J}$ Boczkowski, ${ }^{1,6}$ M Bonay ${ }^{1,7}$
}

- Additional details of the methodology are published online only at http://thorax.bmj. com/content/vol63/issue10

${ }^{1}$ Inserm, U700, Université Paris 7. Faculté de Médecine Denis Diderot-site Bichat, Paris, France; ${ }^{2}$ Services de Biochimie A, Hôpital Bichat, Assistance Publique-Hôpitaux de Paris (AP HP) et Université Paris 7 Denis Diderot, Paris, France;

${ }^{3}$ Pneumologie A, Hôpital Bichat, Assistance Publique-Hôpitaux de Paris (AP-HP) et Université Paris 7 Denis Diderot, Paris, France;

${ }^{4}$ Pneumologie B, Hôpital Bichat, Assistance Publique-Hôpitaux de Paris (AP-HP) et Université Paris 7 Denis Diderot, Paris, France;

${ }^{5}$ Chirurgie Thoracique, Hôpital

Bichat, Assistance Publique-

Hôpitaux de Paris (AP-HP) et

Université Paris 7 Denis Diderot,

Paris, France; ${ }^{6}$ Centre

d'Investigation Clinique 007 et

Hôpital Bichat, Assistance

Publique-Hôpitaux de Paris (AP-

HP) et Université Paris 7 Denis

Diderot, Paris, France;

${ }^{7}$ Physiologie-Explorations

Fonctionnelles, Hôpital Bichat,

Assistance Publique-Hôpitaux de

Paris (AP-HP) et Université Paris

7 Denis Diderot, Paris, France

Correspondence to:

Dr M Bonay, Inserm U700,

Faculté de Médecine Paris 7

Site X Bichat, BP416, 75870

Paris Cedex 18, France;

marcel.bonay@bch.aphp.fr

$D G$ and $A B$ contributed equally to this study.

Received 25 September 2007

Accepted 30 April 2008

Published Online First

17 June 2008

\begin{abstract}
Background: 0xidative stress, resulting from the increased oxidative burden and decreased level of antioxidant proteins, plays a role in the pathophysiology of smoking-related pulmonary emphysema. Expression of several antioxidant proteins, such as heme oxygenase-1 (HO-1), glutathione peroxidase 2 (GPX2) and $\mathrm{NAD}(\mathrm{P}) \mathrm{H}$ :quinone oxidoreductase 1 (NQ01), results from an equilibrium created by positive or negative regulation by the transcription factors Nrf2, Keap1 and Bach1, respectively. However, whether the expression of these transcription factors is altered in emphysema and could account for decreased expression of antioxidant proteins is not known. A study was undertaken to investigate the expression and subcellular localisation of Nrf2, Keap1 and Bach1 as potential regulators of HO-1, GPX2 and N001 in alveolar macrophages, a key cell in oxidative stress, in lung surgical specimens from non-smokers without emphysema and smokers with and without emphysema.
\end{abstract} Methods and results: Western blot, immunohistochemical and laser scanning confocal analysis revealed that the Nrf2 protein level decreased significantly in whole lung tissue and alveolar macrophages (cytosol and nucleus) in patients with emphysema compared with those without emphysema. Conversely, Bach1 and Keap1 levels were increased in patients with emphysema. These modifications were associated with a parallel decrease in the expression of H0-1, GPX2 and N001 at the cellular level, which was inversely correlated with airway obstruction and distension indexes, and increased macrophage expression of the lipid peroxidation product 4-hydroxy-2-nonenal. Silencing RNA experiments in vitro in THP-1 cells were performed to confirm the cause-effect relation between the loss of $\mathrm{Nrf} 2$ and the decrease in $\mathrm{HO}$ 1, N001 and GPX2 expression. Nrf2/Keap1-Bach1 equilibrium was altered in alveolar macrophages in pulmonary emphysema, which points to a decreased stress response phenotype.

Conclusions: This finding opens a new view of the pathophysiology of emphysema and could provide the basis for new therapeutic approaches based on preservation and/or restoration of such equilibrium.

Chronic cigarette smoking is the most important risk factor for lung emphysema, a major component of morbidity and mortality in chronic obstructive pulmonary disease (COPD). ${ }^{1}$ Several mechanisms by which chronic exposure to cigarette smoke (CS) leads to emphysema include lung inflammation and imbalance in level of proteases/ antiproteases and oxidants/antioxidants (namely, oxidative stress). ${ }^{2}$ However, the precise nature of these alterations is still unknown.
Alveolar macrophages are important components of lung inflammation in emphysema. Studies of emphysematous lung tissue from human subjects have shown a direct relation between alveolar macrophage density in the parenchyma and severity of lung destruction. ${ }^{3}$ Moreover, in the emphysematous lung, alveolar macrophages can release an array of matrix metalloprotease enzymes and reactive oxygen species involved in protease/antiprotease imbalance and oxidative stress. ${ }^{4}$

In oxidative stress, phase 2 enzyme systems such as $\mathrm{NAD}(\mathrm{P}) \mathrm{H}$ :quinone oxidoreductase 1 (NOO1), glutathione peroxidase 2 (GPX2) and heme oxygenase-1 (HO-1) are induced to provide antioxidant and anti-inflammatory effects. ${ }^{5}$ This process is mediated by binding of nuclear factor erythroid 2-related factor 2 (Nrf2) to antioxidant response element (ARE) sequence. ${ }^{6}$ Under basal conditions, Nrf2 is sequestered in the cytoplasm and binds to the actin cytoskeleton by the Kelch-like ECHassociated protein 1 (Keap1) which facilitates its proteasomal degradation. ${ }^{6}$ In the presence of oxidative or xenobiotic stimuli, Nrf2 and Keap1 dissociate and Nrf2 migrates into the nucleus. Deficiency of Nrf2 was recently shown to enhance susceptibility to neutrophil elastase and CSinduced emphysema in mice. ${ }^{78}$ However, no data exist on the involvement of Nrf2, Keap1 in human lung emphysema. Furthermore, expression of phase 2 genes like HO- 1 is also under the control of the transcription factor Bach1 which represses the transcription of $\mathrm{HO}-1 .{ }^{9}$

Among oxidative stress-induced phase 2 enzymes, HO-1 is mainly expressed in macrophages within the lung ${ }^{5}$ and plays a central role in the defence against lung oxidative and inflammatory insults, including CS exposure. ${ }^{10}{ }^{11}$ In patients with severe COPD, the expression of HO-1 was significantly decreased in alveolar macrophages ${ }^{12} 13$ but the molecular mechanisms are unknown. This phenomenon has important implications since it can potentiate the inflammatory and oxidative capacities of macrophages.

Given the critical role of Nrf2/Keap1 and Bach1 transcription factors in controlling phase 2 enzymes, an altered level of Nrf2/Keap1 and Bach1 in lung macrophages could account for a decreased HO-1 expression in human emphysema. We aimed therefore to investigate the expression and subcellular localisation of $\mathrm{Nrf} 2 / \mathrm{Keap} 1$ and Bach1 as potential regulators of $\mathrm{HO}-1$ expression in macrophages in lung surgical specimens of nonsmokers without emphysema and smokers with and without emphysema. To further examine the 
consequences of altered expression of Nrf2/Keap1 and Bach1, we also analysed the expression of NOO1 and GPX2, other antioxidant phase 2 enzymes induced by CS in the lung. ${ }^{14}{ }^{15}$ Immunostaining with 4-hydroxy-2-nonenal (4-HNE), a specific and stable end product of lipid peroxidation and a marker of oxidative stress, ${ }^{16}$ was used to assess oxidative damage in the lungs of patients. ${ }^{17}$

Finally, we performed silencing RNA experiments in vitro in THP-1 macrophages incubated with Nrf2 siRNA to verify that Nrf2 participates in the expression of HO-1, NOO1 and GPX2 genes.

\section{METHODS}

See online supplement for further details.

\section{Patients}

Ten patients with severe emphysema (SE) requiring surgery for lung transplantation $(n=2)$ or lung volume reduction $(n=8)$ were included (table 1). Pulmonary function tests demonstrated severe airflow obstruction and lung distension (table 2). According to the GOLD classification of severity (www.goldcopd.com), patients with severe emphysema belong to stage 3 (severe) or 4 COPD (very severe).

Normal lung tissue was obtained from 20 patients without radiological, spirometric or histological features of emphysema $(\mathrm{NE})$. Nine patients were smokers (NE-S) and 11 were nonsmokers (NE-NS).

The study was approved by the local ethics committee of Saint Germain en Laye and stored biopsies were reported to our institutional board (Délégation à la Recherche Clinique, Assistance Publique-Hôpitaux de Paris).

\section{Processing of lung samples}

Lung tissue fragments were immediately frozen in liquid nitrogen and stored at $-80^{\circ} \mathrm{C}$. The histopathology of biopsies was evaluated on paraffin-embedded sections to verify features of emphysema or normal lung.

\section{Quantitative RT-PCR analysis}

HO-1, HO-2, GPX2 and NOO1 mRNA expression was quantified by RT-PCR (MX3000P, Stratagene, La Jolla, California, USA) as described elsewhere ${ }^{18}$ and expressed as a ratio to ubiquitin-c (see table III in online supplement).

\section{Preparation of lung homogenates for Western blot analysis}

Lung biopsy samples were homogenised in $10 \mathrm{mM}$ Tris- $\mathrm{HCl}, \mathrm{pH}$ $6.8,1 \% \mathrm{SDS}, 5 \%$ glycerol. Aliquots were stored at $-80^{\circ} \mathrm{C}$ with $10 \%$ Protease Inhibitor Cocktail (Sigma, France). Western blot analysis was performed as described elsewhere ${ }^{19}$ with anti-Nrf2, Keap1, Bach1 (Santa-Cruz Biotechnology, Santa Cruz, California, USA), and anti-HO-1, HO-2 antibodies (Stressgen, Le-Perray-en-Yvelines, France). The results are expressed as a ratio to $\beta$-actin expression (Sigma, St Louis, Missouri, USA).

\section{Immunohistochemical analysis}

Immunohistochemistry with the primary antibodies anti-Nrf2, Bach1, Keap1, HO-1 and anti- CD68 (macrophage marker) (Dako, Glostrup, Denmark, Clone PG-M1) was performed as previously described. ${ }^{20}$ On adjacent sections, positive cells with characteristic macrophage morphology were evaluated by two independent observers in 10 different high power fields at $\times 200$ magnification, and results were expressed as the number of positive cells per $\mathrm{mm}^{2}$ lung tissue.

\section{Confocal laser scanning microscopy}

Double immunofluorescence labelling was performed to colocalise CD68, HO-1 and 4-HNE with Nrf2, Bach1 and Keap1, as previously described. ${ }^{21}$ The intensity of nuclear Nrf2, Bach1 and cellular HO-1, Keap1 and 4-HNE immunofluorescence was quantified in macrophages.

\section{siRNA transfection}

THP-1 cells were transfected with 300 nM Nrf2 siRNA (NM_006164; Dharmacon SMARTpool siRNA reagent) or negative control siRNA (Dharmacon plus non-targeting pool) using Transpass R2 transfecting reagent according to the manufacturers' instructions. Cells were lysed and nuclear and cytosolic fractions were prepared as previously described. ${ }^{22}$

\section{Statistical analysis}

Data were analysed by Statview software (Abacus Concepts) and displayed as medians and ranges. Between-group differences were first assessed by non-parametric analysis of variance (Kruskal-Wallis test) and Mann-Whitney U-test. Correlations were assessed by Spearman's rank order test. Categorical data were analysed by $\chi^{2}$ test. $p$ Values of $<0.05$ were considered significant.

\section{RESULTS}

\section{Nrf2/Keap1 and Bach1 protein expression in the lung}

We first analysed the expression of Nrf2, Keap1 and Bach1 at the protein level in whole lung homogenates. Western blot analysis showed decreased Nrf2 protein in the SE group compared with the NE groups (fig 1). By contrast, the level of Keap1 and Bach1 protein was increased in the SE group compared with the NE groups.

Table 1 Clinical characteristics

\begin{tabular}{|c|c|c|c|c|}
\hline & $\begin{array}{l}\text { Non-smokers without } \\
\text { emphysema (NE-NS) } \\
\text { (n-11) }\end{array}$ & $\begin{array}{l}\text { Smokers without } \\
\text { emphysema (NE-S) } \\
(\mathrm{n}=9)\end{array}$ & $\begin{array}{l}\text { Patients with severe } \\
\text { emphysema (SE) } \\
(\mathrm{n}=10)\end{array}$ & $\begin{array}{l}\text { Between group } \\
\text { differences ( } p \text { value) }\end{array}$ \\
\hline $\begin{array}{l}\text { Median (range) age } \\
\text { (years) }\end{array}$ & $58(32-72)$ & $58.5(30-68)$ & $57.5(49-65)$ & 0.99 \\
\hline Sex ratio (F/M) & $2 / 9$ & $0 / 9$ & $1 / 9$ & 0.28 \\
\hline $\begin{array}{l}\text { Median (range) no of } \\
\text { packs smoked }\end{array}$ & 0 & $37.5(10-50) \$$ & $52(20-100)+\hbar$ & $10^{-4}$ \\
\hline $\begin{array}{l}\text { Time since smoking } \\
\text { cessation (years) }\end{array}$ & NA & $0(0-20)$ & $1(0-8)$ & 0.88 \\
\hline $\begin{array}{l}\text { Current smokers/ex- } \\
\text { smokers }\end{array}$ & NA & $7 / 2$ & $2 / 8$ & $10^{-4}$ \\
\hline
\end{tabular}


Table 2 Pulmonary function tests

\begin{tabular}{|c|c|c|c|c|}
\hline & $\begin{array}{l}\text { Non-smokers without } \\
\text { emphysema (NE-NS) } \\
\text { ( } \mathrm{n}=11 \text { ) }\end{array}$ & $\begin{array}{l}\text { Smokers without } \\
\text { emphysema (NE-S) } \\
\text { ( } \mathrm{n}=9)\end{array}$ & $\begin{array}{l}\text { Patients with severe } \\
\text { emphysema (SE) } \\
\text { (n=10) }\end{array}$ & $\begin{array}{l}\text { Between group } \\
\text { differences ( } p \text { value) }\end{array}$ \\
\hline $\mathrm{FEV}_{1} \%$ predicted (\% pred) & $79(68-101)$ & $78(60-110)$ & $22(13-47) \dagger \dagger$ & $10^{-4}$ \\
\hline $\mathrm{FEV}_{1} / \mathrm{FVC}$ & $90(71-105)$ & $68(64-85) \ddagger$ & $43.5(35-50)+\$$ & $10^{-4}$ \\
\hline RV (\% pred) & $95(55-117)$ & $117(96-132)$ & $241(207-349) \dagger$ & $10^{-4}$ \\
\hline TLC (\% pred) & 82.5 (76-99) & $100(84-116) \ddagger$ & $130(110-153) \dagger$ & $10^{-4}$ \\
\hline $\mathrm{PaO}_{2}(\mathrm{kPa})$ & $11.4(10.1-12.4)$ & $11.3(10.1-13.3)$ & $9(7.3-10.9) \dagger+$ & $8.10^{-4}$ \\
\hline $\mathrm{PaCO}_{2}(\mathrm{kPa})$ & $5.5(5.1-6)$ & $5.3(4.8-6.1)$ & $5.7(4.5-6.7)$ & 0.36 \\
\hline TLCo (\% pred) & Not done & Not done & $43.5(15-67)$ & Non-relevant \\
\hline 6 min walk test $(\mathrm{m})$ & Not done & Not done & $350(70-540)$ & Non-relevant \\
\hline
\end{tabular}

$\dagger p=10^{-4}$ vs NE-S; $t p=10^{-4}$ vs NE-NS as assessed by the Mann-Whitney U-test.

$\mathrm{FEV}_{1}$, forced expiratory volume in $1 \mathrm{~s}$; $\mathrm{FVC}$, forced vital capacity; $\mathrm{PaO}_{2}$, arterial oxygen tension; $\mathrm{PaCO}_{2}$, arterial carbon dioxide tension; RV, residual volume; TLC, total lung capacity; TLCO, carbon monoxide lung transfer factor.

\section{Subcellular localisation of Nrf2/Keap1 and Bach1 in alveolar macrophages}

We investigated whether our findings of decreased Nrf2 and increased Keap1 and Bach1 protein expression in whole lung homogenates would be reflected at the macrophage level and whether they concerned nuclear localisation of the transcription factors. As macrophages play a critical role in the pathophysiology of emphysema, ${ }^{34}$ we focused on these cells. We quantified the macrophages in our samples by detecting CD68 positive cells on immunohistochemistry. The number of CD68 positive cells was significantly increased in the SE group $\left(166 / \mathrm{mm}^{2}\right.$ (range 135-180)) compared with the NE-NS (81/ $\mathrm{mm}^{2}$ (range 80-87)) and NE-S groups (120/ $\mathrm{mm}^{2}$ (100-121)) $(p=0.04$ vs NE-S and $p=0.01$ vs NE-NS; see fig E1 in the online supplement), as was found previously. ${ }^{3}$ Alveolar macrophages, alveolar epithelial cells and endothelial cells were positive for Nrf2 in the NE-NS and NE-S groups. However, semi-quantitative analysis revealed higher staining
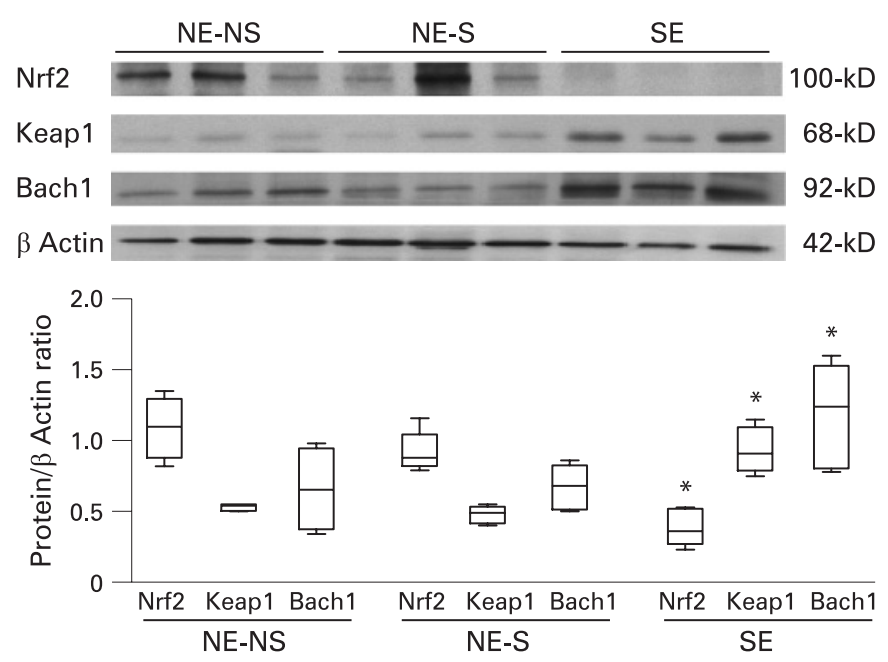

Figure 1 Expression of Nrf2, Keap1 and Bach1 in lung tissue. Box and whiskers plots with median, interquartile range and minimum and maximum values. Top: representative western blot of Nrf2, Keap1 and Bach1 protein expression of lung homogenates from three NE-NS patients, three NE-S patients and three SE patients with the respective $\beta$ actin controls. Bottom: quantification of Nrf2, Keap1 and Bach1 protein. Results are expressed as a ratio to $\beta$ actin protein concentration $(n=6$, Nrf2 and Keap1; ${ }^{*} p=0.004$ vs NE groups; Bach1 ${ }^{*} p=0.016$ vs NE-S and $p=0.049$ vs NE-NS, respectively). NE-NS and NE-S, patients without emphysema non-smokers and smokers, respectively; $\mathrm{SE}$, patients with severe emphysema. of macrophages than other cell types $(p=0.04)$. The number of CD68 positive cells with positive Nrf2 staining was decreased in the SE group (19.9\% (16.3-25.6)) compared with the NE-NS (98.8\% (98.3-100)) and NE-S groups (99\% (98.999.6) groups; $p=0.029)$. By contrast, the number of CD68 positive cells with positive Bach1 or Keap1 staining was increased in the SE group compared with the NE-NS and NE-S groups (Bach1: 89.2\% (70.5-98.9) vs 15\% (8.6-24.1) and 10.8\% (9.1-11.1); $p=0.03$; Keap1: $92.8 \%(89.2-95.8)$ vs $12.3 \%(10-$ $18.4)$ and $11.7 \%(10.1-11.7) ; p=0.03)$. Confocal laser microscopy with double immunofluorescence labelling confirmed the co-localisation of CD68 with Nrf2, Bach1 or Keap1 expression in alveolar macrophages from NE-NS, NE-S and SE patients (fig 2). Nrf2 expression was profoundly decreased in both the cytosol and nucleus of alveolar macrophages of SE compared with the NE groups (fig 2A), with no difference between the NE-NS and NE-S groups. Bach1 and Keap1 expression was increased in both the cytosol and nucleus of alveolar macrophages of the SE group compared with the $\mathrm{NE}$ groups (fig $2 \mathrm{~B}$ and $\mathrm{C}$ ), with no difference in expression between the NE-NS and NE-S groups. Quantification of nuclear Nrf2, Bach1 and cellular Keap1 immunofluorescence confirmed decreased Nrf2, increased Bach1 and increased Keap1 in the SE group compared with the NE groups (fig 2D).

\section{Heme oxygenase expression}

Having demonstrated decreased cytosolic and nuclear Nrf2 and increased Bach1 and Keap1 immunostaining in lung macrophages of the SE group, we investigated whether these alterations were associated with decreased expression of $\mathrm{HO}$ 1. HO-1 mRNA expression in whole lung homogenates was markedly decreased in the SE group compared with the NE groups (fig 3A). By contrast, the constitutive isoform $\mathrm{HO}-2$ was expressed similarly in all groups (fig $3 \mathrm{~B}$ ). The HO-1 mRNA level was strongly and inversely correlated with airway obstruction and lung distension (rho for forced expiratory volume in $1 \mathrm{~s}$ $\left(\mathrm{FEV}_{1}\right)+0.54, \mathrm{p}=0.003$; ratio of $\mathrm{FEV}_{1}$ to forced vital capacity $\left(\mathrm{FEV}_{1} / \mathrm{FVC}\right)+0.51, \mathrm{p}=0.0046$; residual volume $(\mathrm{RV})-0.51$, $p=0.005$; total lung capacity (TLC) $-0.49, p=0.008$ ). These correlations persisted when non-smokers were excluded (rho for $\mathrm{FEV}_{1}+0.592, \mathrm{p}=0.012 ; \quad \mathrm{FEV}_{1} / \mathrm{FVC}+0.618, \mathrm{p}=0.009 ; \mathrm{RV}$ $-0.624, p=0.01$; TLC $-0.595, p=0.014)$. Furthermore, western blot analysis confirmed decreased HO-1 mRNA expression, with decreased protein expression in the SE group compared with the NE groups (fig 3C). No significant difference was observed for $\mathrm{HO}-2$ protein between groups. 
A

Nrf2
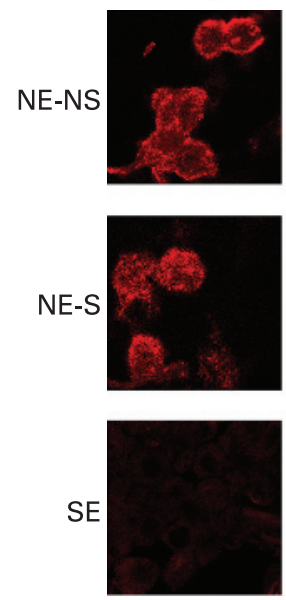

B
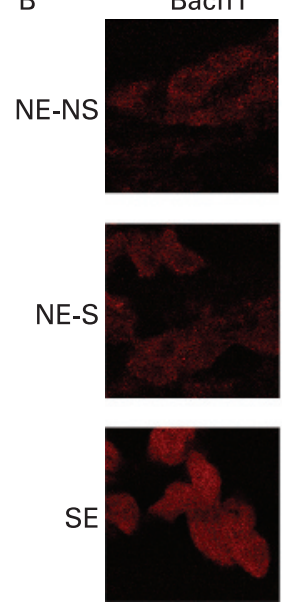

C
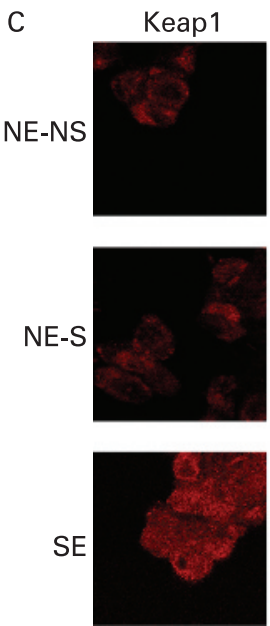

$\mathrm{CD} 68$
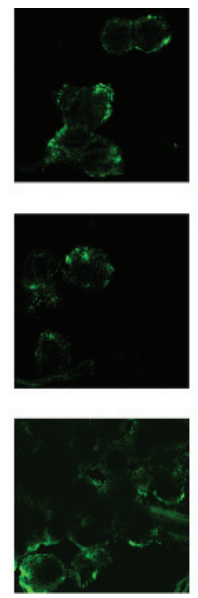

CD68
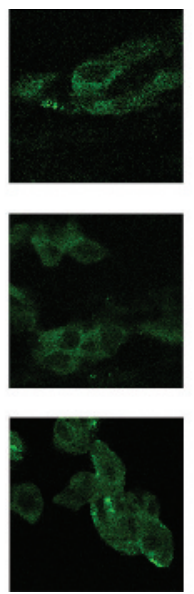

CD68
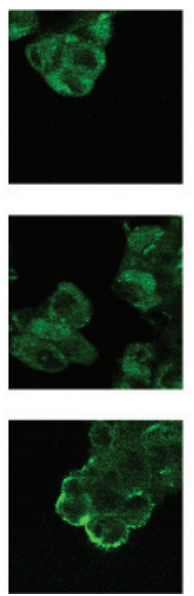
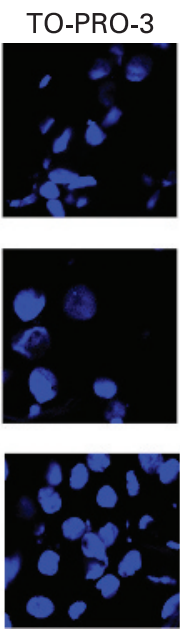

TO-PRO-3
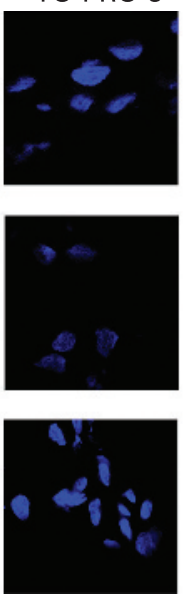

TO-PRO-3
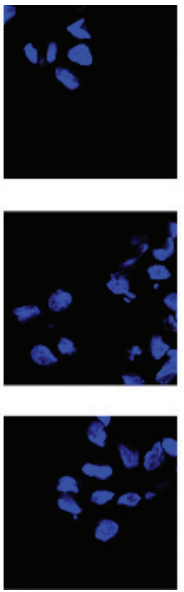
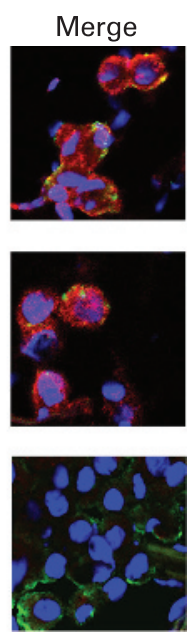

Merge
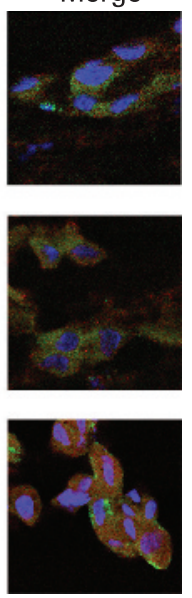

Merge
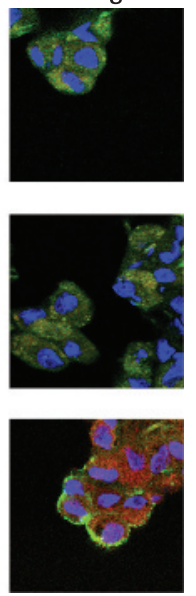

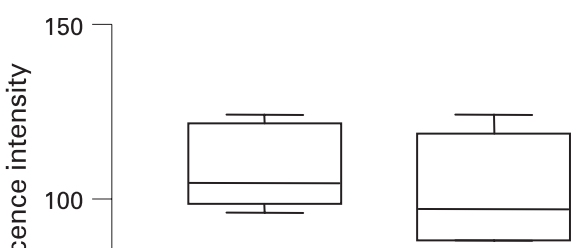

$50-$
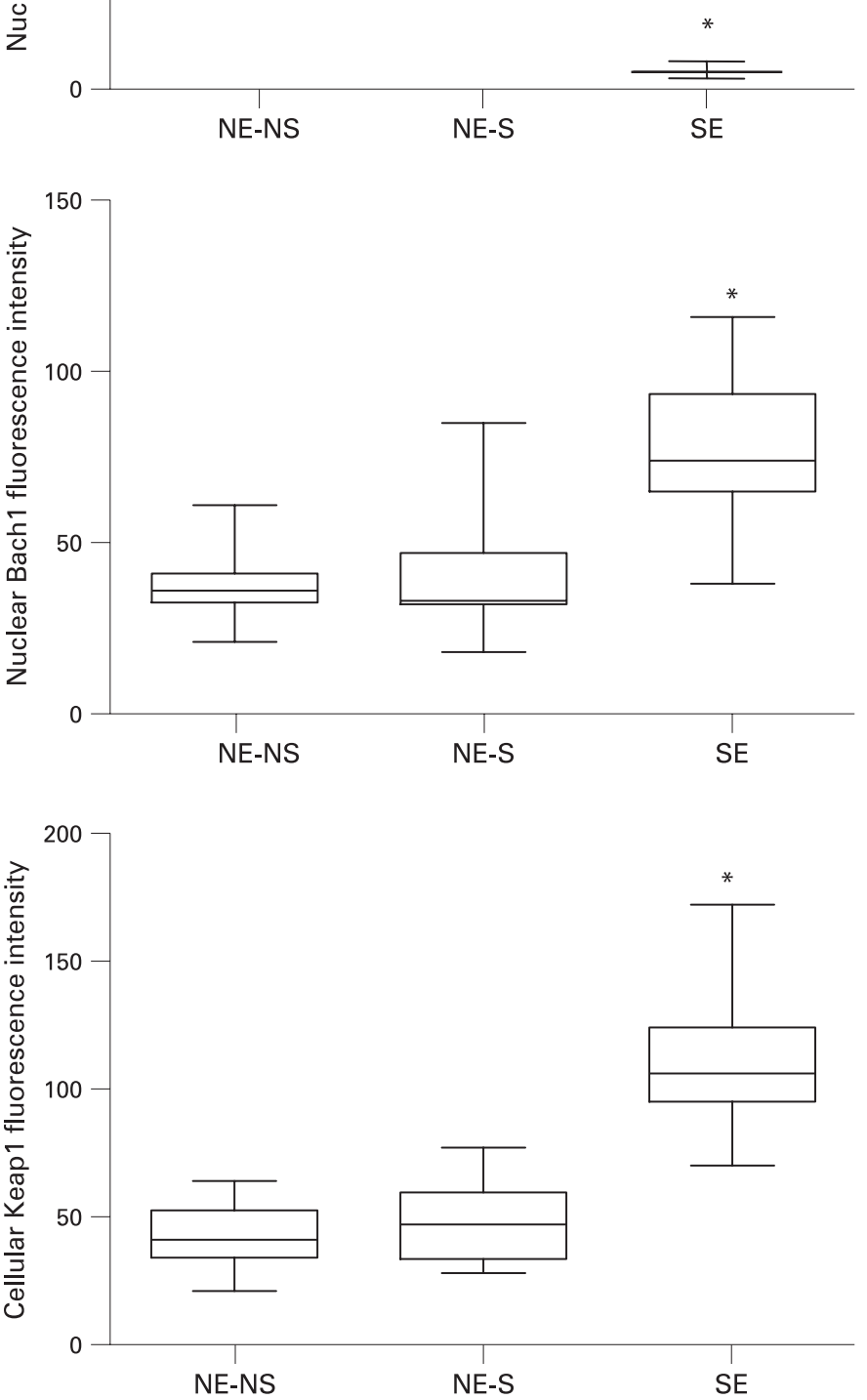

Figure 2 Laser confocal microscopy analysis of lung biopsies. Immunofluorescent staining was performed with Nrf2, Bach1, Keap1 (in red: left column) and CD68 (in green) and TO-PRO-3 DNA stain (blue). Co-expression is seen by double staining and overlays (Merge column). (A) Nrf2; (B) Bach1; (C) Keap1; (D) Quantification of Nrf2 and Bach1 nuclear and cellular Keap1 immunofluorescence in macrophages of NE-NS, NE-S and SE patients (magnification $\times 1200$ ). Box and whisker plot with median, interquartile range and minimum and maximum values. ${ }^{*} p=10^{-4}$ vs $N E$ groups. Images are representative of all samples. NE-NS and NE-S, patients without emphysema non-smokers and smokers, respectively; SE, patients with severe emphysema.

Co-localisation of Nrf2/Keap1 and Bach1 with H0-1 in alveolar macrophages

We initially verified the expression of $\mathrm{HO}-1$ in alveolar macrophages on immunostaining with a CD68 antibody in sequential slides. Most of the $\mathrm{HO}-1$-positive cells in alveolar spaces were CD68 positive (88.5\% (75.6-94.2)), as reported previously. ${ }^{23}$ Co-localisation experiments on laser confocal miscroscopy revealed that $\mathrm{HO}-1$ expression paralleled that of $\mathrm{Nrf2}$; the HO-1 level was decreased concomitantly with a decreased level of Nrf2 in alveolar macrophages in the SE group 
Figure 3 Expression of (A) H0-1 mRNA and (B) H0-2 mRNA in lung tissue. Box and whiskers plot with median, interquartile range and minimum and maximum values. Results are expressed ${ }^{*} p=0.02$ vs NE-NS and $p=0.002$ vs NE-S. (C) Top: Representative western blot of $\mathrm{HO}-1$ and $\mathrm{HO}-2$ protein expression of lung homogenates from three patients with NE-NS, three NE-S and three SE patients with the respective $\beta$ actin controls. Bottom: Quantification of $\mathrm{HO}-1$ as a ratio to $\beta$ actin protein concentration ( $n=6,{ }^{*} p=0.004$ vs NE groups.) NE-NS and NE-S, patients without emphysema non-smokers and smokers, respectively; $\mathrm{SE}$, patients with severe emphysema. as a ratio to ubiquitin mRNA levels. and $\mathrm{HO}-2$ protein. Results are expressed
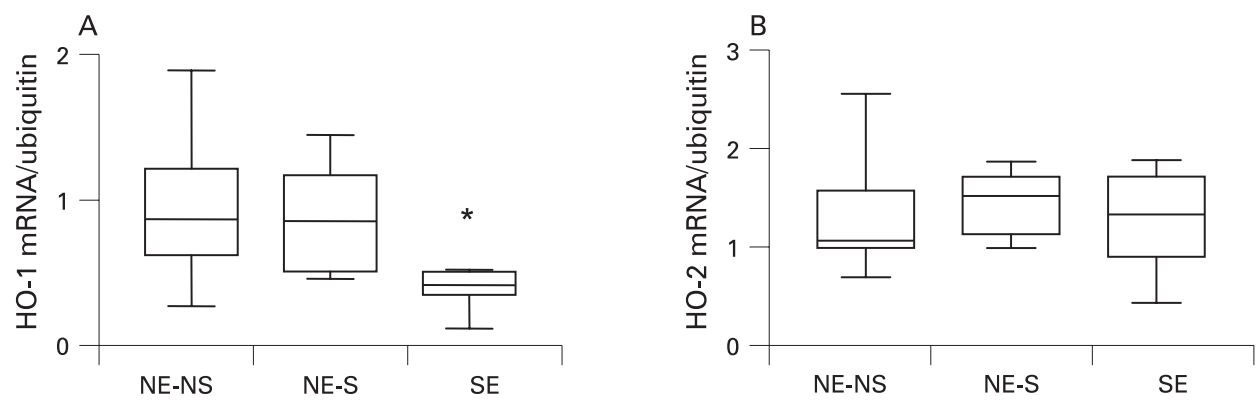

C

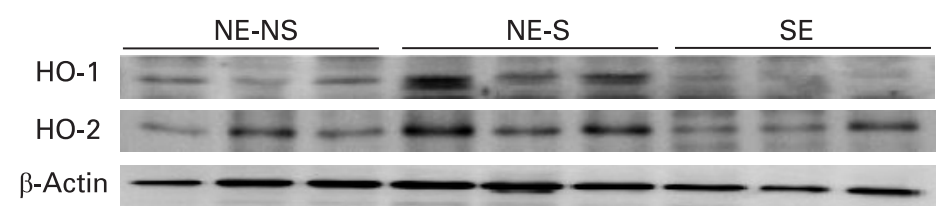

$32-k D$ $36-\mathrm{kD}$ 42-kD
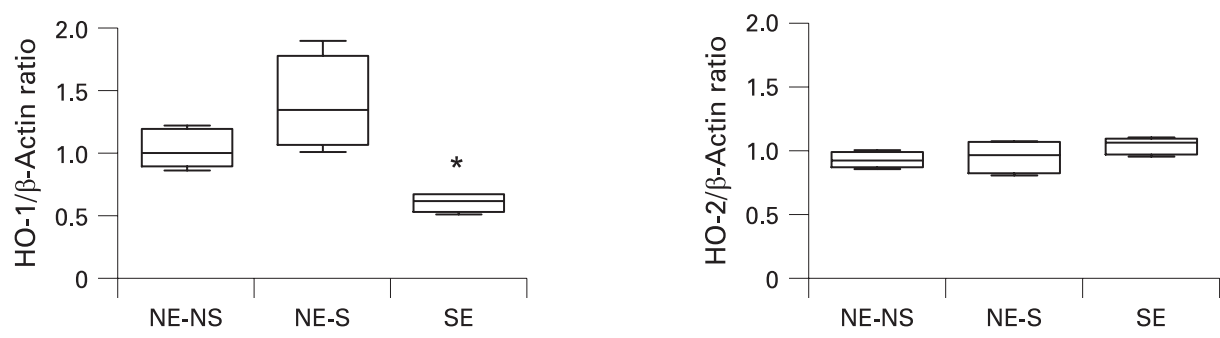

(fig 4A). Moreover, in alveolar macrophages from patients with $\mathrm{SE}$, increased Bach1 and Keap1 expression was associated with decreased $\mathrm{HO}-1$ expression (fig 4B and C). Immunofluorescence quantification showed decreased $\mathrm{HO}-1$ expression associated with decreased level of nuclear Nrf2, increased level of nuclear Bach1 and cellular Keap1 in macrophages of the SE group compared with the NE groups (fig 4D). HO-1 was expressed in the cytosol and membrane in macrophages of the NE groups.

\section{N001 and GPX2 mRNA expression}

To further examine the consequences of altered expression of Nrf2/Keap1 and Bach1, we investigated the mRNA expression of the Nrf2-regulated antioxidant genes NOO1 and GPX2. The NQO1 and GPX2 mRNA level was decreased in the SE group compared with the NE groups (fig 5). Similar to the results for HO-1, the NOO1 and GPX2 mRNA level was inversely correlated with airway obstruction and lung distension (NQO1: rho for $\mathrm{FEV}_{1}+0.39, \mathrm{p}=0.02 ; \mathrm{FEV}_{1} / \mathrm{FVC}+0.36$, $\mathrm{p}=0.04 ; \mathrm{RV}-0.44, \mathrm{p}=0.015 ;$ TLC $-0.40, \mathrm{p}=0.03$; GPX2: rho for $\mathrm{FEV}_{1}+0.368, \mathrm{p}=0.027 ; \mathrm{FEV}_{1} / \mathrm{FVC}+0.357, \mathrm{p}=0.032 ; \mathrm{RV}$ $-0.544, p=0.001$; TLC $-0.502, p=0.003)$. These correlations persisted when non-smokers were excluded for NOO1 (data not shown).

\section{Co-localisation of Nrf2 with 4-HNE in alveolar macrophages}

Immunostaining with 4-HNE was used to assess oxidative damage in the lungs. Co-localisation experiments on laser confocal miscroscopy and immunofluorescence quantification revealed that increased 4-HNE expression was associated with a decreased level of nuclear Nrf2 in alveolar macrophages of the SE group compared with the NE groups (fig 6). 4-HNE staining was positive in both the cytosol and membrane in macrophages of the SE group.
Nrf2 silencing in THP-1 cells (figs E2-4 in online supplement) Western blot analysis confirmed that Nrf2 siRNA transfection induced a time course inhibition of cellular Nrf2 of $55 \%$ of control cells at $8 \mathrm{~h}$, associated with a subsequent decrease in $\mathrm{HO}-1$ to $38 \%$ and $41 \%$ of control cells at $12 \mathrm{~h}$ and $24 \mathrm{~h}$, respectively (fig $\mathrm{E} 2$ in online supplement). The decrease in Nrf2 was confirmed in both cytosolic and nuclear compartments by western blot and confocal analysis (fig E3 in online supplement). Moreover, confocal double immunostaining confirmed the concomitant decrease in Nrf2 and HO-1 expression. To further examine the consequences of Nrf2 silencing, we showed that the mRNA expression of Nrf2-regulated antioxidant genes HO-1, NOO1 and GPX2 was decreased (fig E4 in online supplement).

\section{DISCUSSION}

In this study we have shown that the protein expression of Nrf2 decreased and that of Keap1 and Bach1 increased in alveolar macrophages of lung specimens from patients with smokingrelated lung emphysema compared with smoking and nonsmoking patients without emphysema. These abnormalities have important implications in human emphysema, since Nrf2 has been shown to play a protective role against neutrophil elastase and cigarette smoke-induced emphysema in animals. ${ }^{78}$ Furthermore, these modifications were associated with a parallel decrease in the antioxidant $\mathrm{HO}-1, \mathrm{NOO} 1$ and GPX2 expressions which were inversely correlated with airway obstruction and lung distension indexes. Decreased Nrf2 expression was associated with increased macrophage expression of the lipid peroxidation product 4-HNE. Given the vast array of protective genes regulated by Nrf2/Keap1 and Bach1 in addition to HO-1, GPX2 and NOO1, the abnormalities we describe point to a phenotype of decreased stress response which could account for the excessive oxidative stress in alveolar macrophages of patients with smoking-related 
A
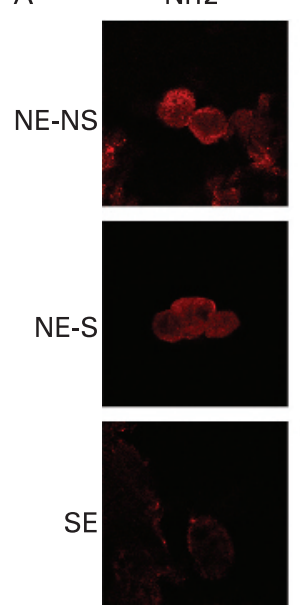

B
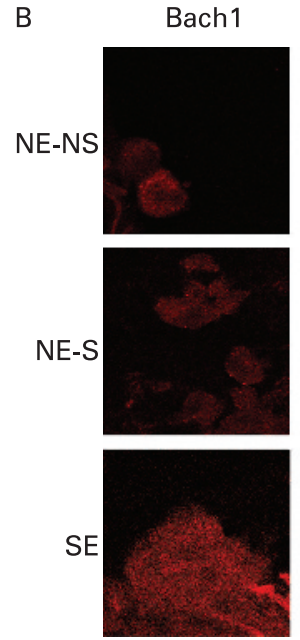

C
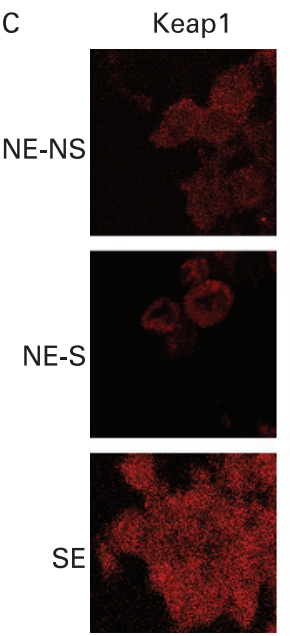
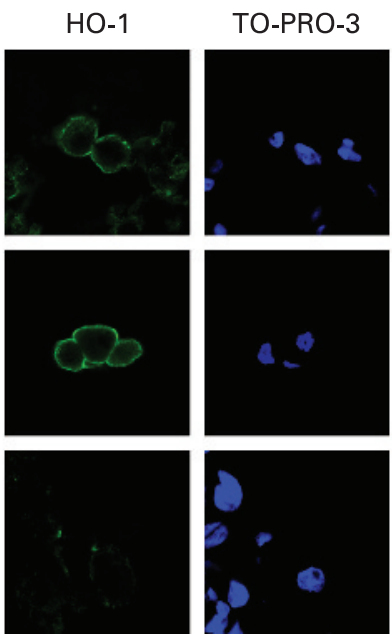

$\mathrm{HO}-1$
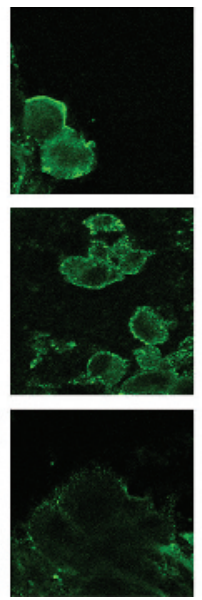

$\mathrm{HO}-1$
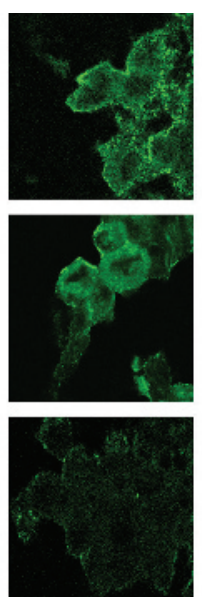
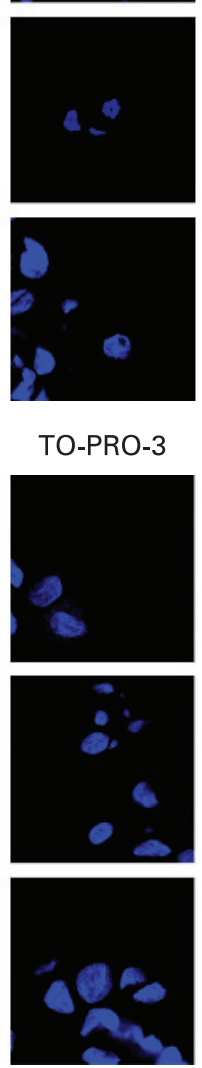

TO-PRO-3
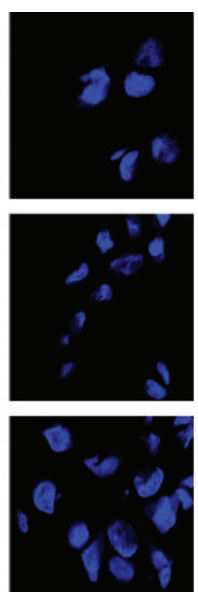

Merge
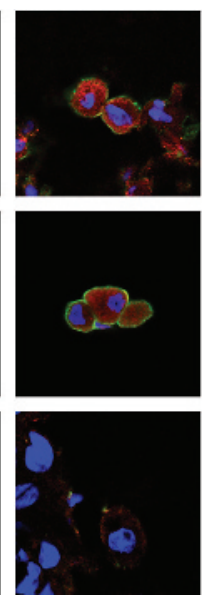

Merge
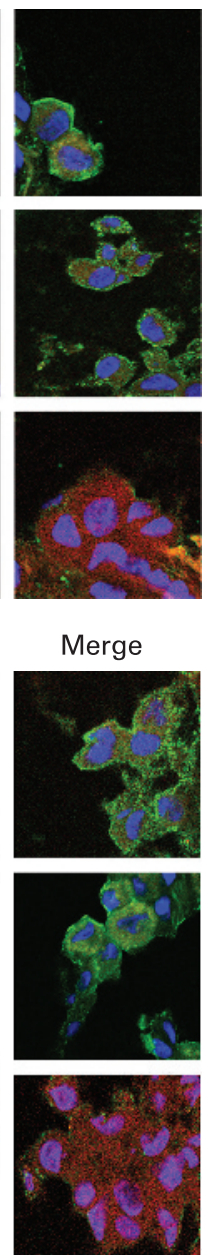

D
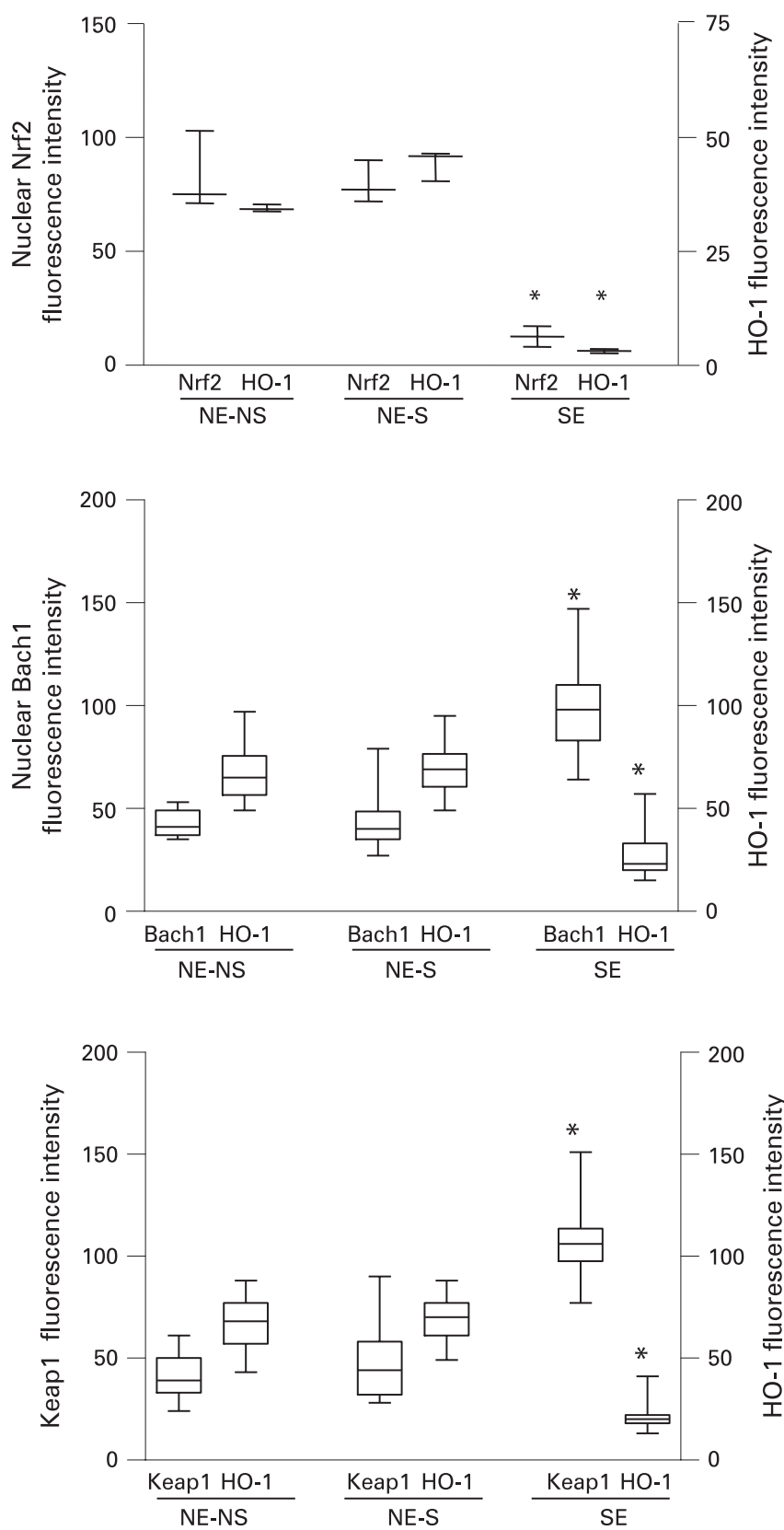

Figure 4 Laser confocal microscopy analysis of lung biopsies. Immunofluorescent staining was performed with Nrf2, Bach1, Keap1 (in red, left column) and H0-1 (in green) and TO-PRO-3 DNA stain (blue). Co-expression is seen by double staining and overlays (Merge column). (A) Nrf2; (B) Bach1; (C) Keap1; (D) Quantification of nuclear Nrf2, nuclear Bach1, cellular Keap1 and cellular H0-1 immunofluorescence in macrophages (magnification $\times 1200$ ). Box and whiskers plot with median, interquartile range and minimum and maximum values. ${ }^{*} \mathrm{p}=10^{-4} \mathrm{vs} \mathrm{NE}$ groups. Images are representative of all samples. NE-NS and NE-S, patients without emphysema non-smokers and smokers, respectively; SE, patients with severe emphysema.

emphysema. This finding provides a new view in the understanding of lung emphysema in particular and COPD in general.

Nrf2/Keap1 and Bach1 lung expression has never been described for humans. Indeed, only one study reported the protein expression of these transcription factors in human tissues. ${ }^{24}$ Although Nrf2 and Bach1 are ubiquitous, we focused on macrophages as key cells in the pathogenesis of lung emphysema. ${ }^{2}{ }^{4}$ Significant changes in Nrf2 and Bach1 proteins in whole lung homogenates from patients with severe emphysema shown by Western blot analysis were confirmed 
Figure 5 Expression of (A) N001 mRNA and (B) GPX2 mRNA in lung tissue. Box and whiskers plot with median, interquartile range and minimum and maximum values. Results are expressed as a ratio to ubiquitin mRNA levels. ${ }^{*} p=0.004$ vs NE-NS and 0.0007 vs NE-S; and $p=0.018$ vs NE-NS and 0.024 vs NE-S for NQ01 and GPX2, respectively. NE-NS and NE-S, patients without emphysema non-smokers and smokers, respectively; SE, patients with severe emphysema.
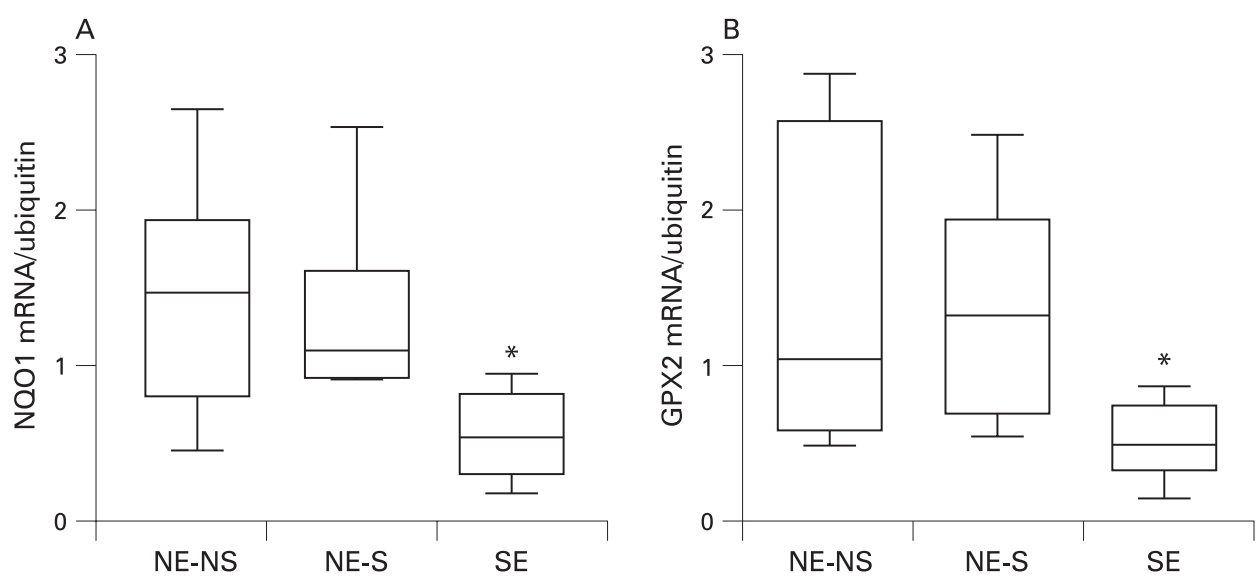

by immunohistochemistry and laser confocal microscopy analysis in macrophages. Some non-macrophage cells showed positive immunostaining for $\mathrm{Nrf2}$, as was found in vitro in endothelial and epithelial cells. ${ }^{25}{ }^{26}$ Although we cannot rule out the participation of non-macrophage cells in lung antioxidant responses via Nrf2, the intensity of such staining in these cells was significantly lower than that in macrophages. Furthermore, Bach1 was expressed almost only in macrophages. Interestingly, Ishii and coworkers found that transplantation of wild-type bone marrow cells expressing Nrf2 into Nrf2-knockout mice instilled with elastase retarded the development of initial lung inflammation and subsequent emphysema. This improvement was associated with the appearance of macrophages expressing Nrf2-regulated antiprotease and antioxidant genes, stressing the importance of the Nrf2 pathway in macrophages.

The decreased nuclear localisation of Nrf2 protein in the macrophages of patients with severe emphysema was concomitant with decreased cytosolic expression, thus showing a global decrease in Nrf2 protein expression rather a localised defect in nuclear localisation. Furthermore, cellular Keap1 protein was increased in macrophages of patients with severe emphysema. Decreased Nrf2 protein expression could have resulted from increased Keap1 protein expression, which accelerated Nrf2 cytosolic degradation, ${ }^{6}$ and/or phosphorylation of nuclear Nrf2 with ensuing nuclear extrusion and cytosolic degradation, as demonstrated in cells exposed to oxidative stressgenerating high UVB light. ${ }^{27}$ The Bach1 protein level was increased in the nucleus and cytosol of macrophages from patients with severe emphysema. As for Nrf2, increased Bach1 protein expression in the macrophages from patients with severe emphysema probably reflects changes in its degradation. Clearly, examination of these mechanisms deserves further study.

Whatever the process leading to the modification in Nrf2/ Keap1 and Bach1 protein expression seen in the alveolar macrophages of patients with emphysema, these findings were associated with a significant decrease in the expression of the downstream cytoprotective phase 2 genes HO-1, GPX2 and NOQ1. We are confident in the strength of this causal relation because, at least for HO-1, double immunolabelling and laser confocal microscopy analysis verified the association between expression of Nrf2, Keap1 and Bach1 and that of HO-1. Silencing RNA experiments in THP-1 macrophages allowed us to confirm a cause-effect relation between the loss of Nrf2 and the decrease in HO-1, NOO1 and GPX2 gene expression.

Consistent with the central role of Nrf2 in the protection of the lungs against oxidative stress, we also showed by double immunolabelling that the decreased expression of Nrf2 was associated with increased macrophage expression of 4-HNE in the lungs of patients with severe emphysema. Thus, an Nrf2dependent transcriptional regulation of antioxidant enzymes in the lungs may play an important role in counteracting CSinduced lung oxidative stress to protect against emphysema.

The decreased HO-1 mRNA and protein expression demonstrates a transcriptional repression of this enzyme and fits well with the decreased number of HO-1 positive alveolar macrophages that Maestrelli and coworkers and Slebos and associates observed in patients with severe COPD..$^{12}{ }^{13}$ Our finding that HO-1 was not increased in smokers without emphysema is unexpected. However, these results agree with the lack of change in Nrf2/Keap1 and Bach1 in these patients and with other results. ${ }^{23}{ }^{28} \mathrm{HO}-1$ protein was expressed in the cytosol and membrane of macrophages of patients without emphysema, a finding never reported before. Although classically expressed in microsomes, ${ }^{29}$ HO-1 has been found expressed in mitochondria $^{30}$ nucleus $^{31}$ and caveolae ${ }^{32}$ of different cell types. Our findings agree with this last localisation and with data showing that carbon monoxide, one of the products of heme degradation by $\mathrm{HO}$, inhibits signalling of cell membrane toll-like receptors in macrophages. ${ }^{33}$ This and other antioxidant and anti-inflammatory effects of HO-1 and related products - such as decreased production of reactive oxygen species ${ }^{21}$ and/or inhibition of metalloprotease-1 expression and activity ${ }^{34}$-can explain its protective role against emphysema in smokers tested experimentally ${ }^{35}$ and in genotype-phenotype studies. ${ }^{10}{ }^{11}$ The antioxidant deficit elicited by decreased HO-1 expression in patients with severe emphysema can be potentiated by decreased expression of NOO1 which is induced by cigarette smoke ${ }^{14}$ and detoxifies quinones, ${ }^{36}$ present in this compound. The pathophysiological importance of decreased HO-1 and NOO1mediated antioxidant and anti-inflammatory effects in our patients with emphysema is stressed by the strong correlation between the decreased mRNA expression of these enzymes and airway obstruction and lung distension indexes.

Our study has some methodological limitations. We studied a limited number of patients in each group. The emphysema group was composed of patients with severe emphysema selected on the basis of surgical recruitment and evaluated at only one time point in the course of the disease. Because only one tissue sample from surgically resected material was available for examination, the expression of transcription factors and HO-1 could reflect regional disease activity and may not represent the entire lung. Indeed, emphysema is well 
A
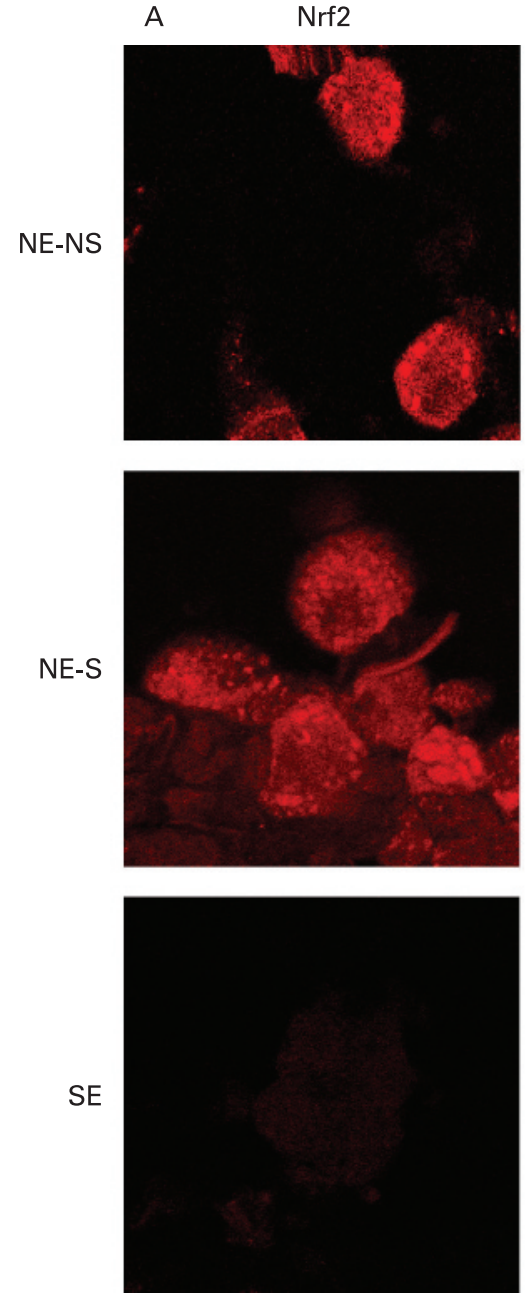

4-HNE
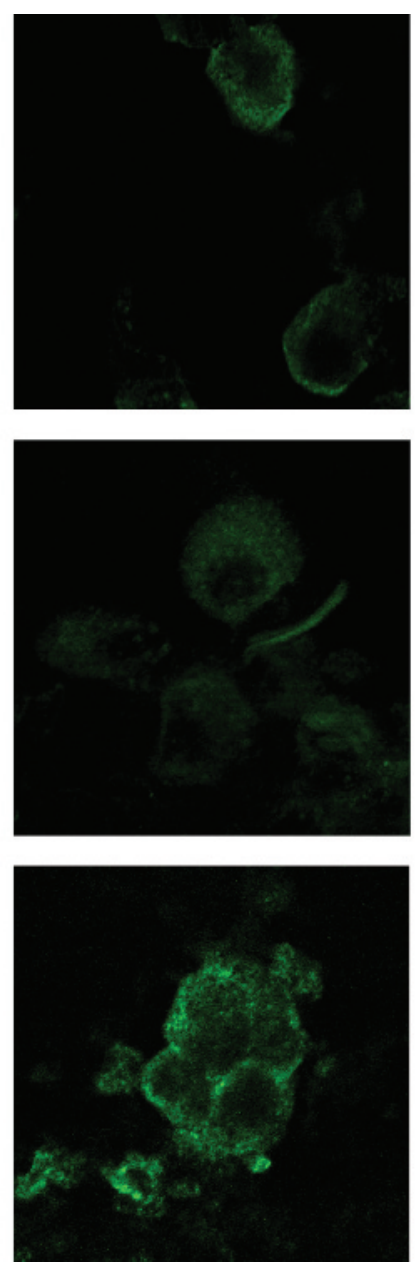

TO-PRO-3
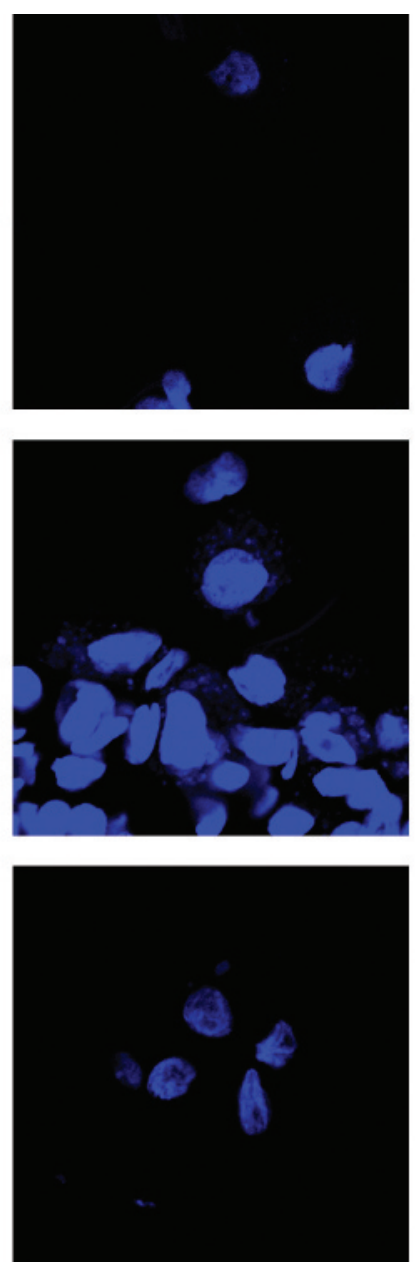
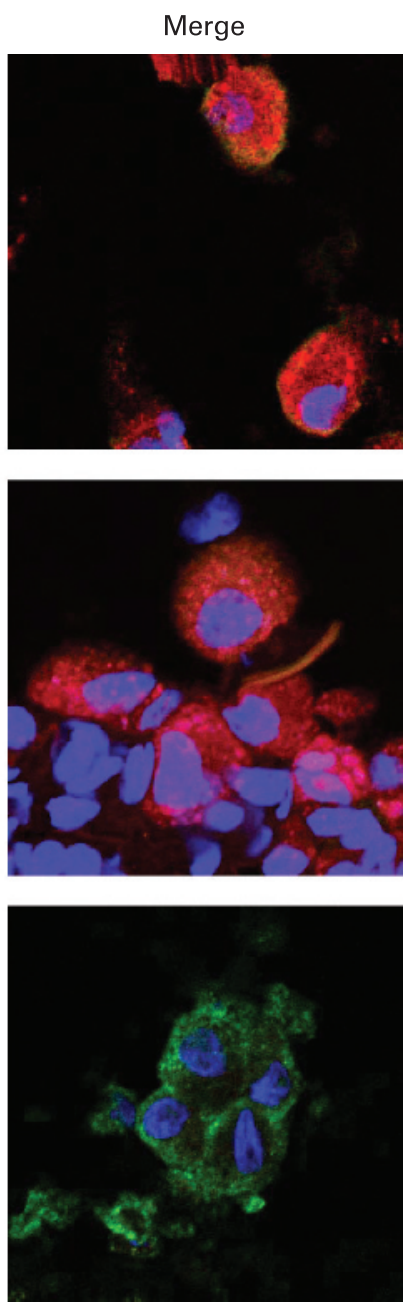

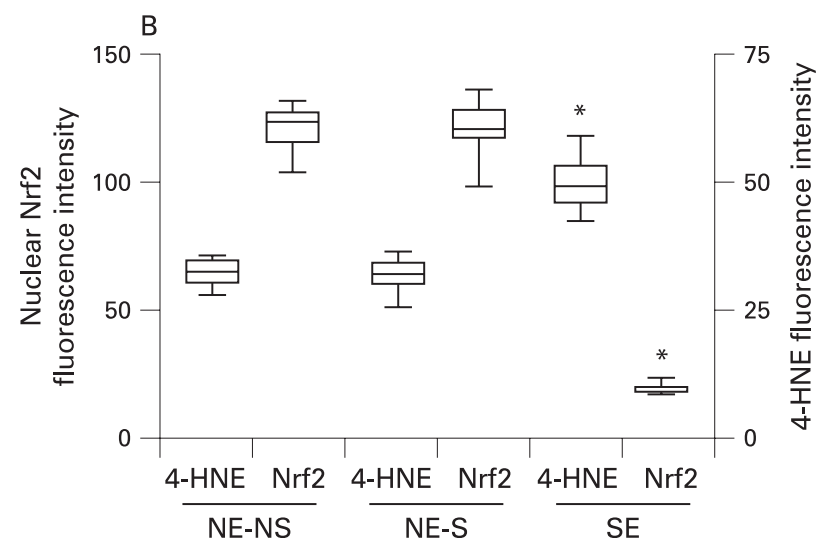

Figure 6 Laser confocal microscopy analysis of lung biopsies. (A) Immunofluorescent staining was performed with Nrf2 (in red, left column) and 4hydroxy-2-nonenal (4-HNE, in green) and TO-PRO-3 DNA stain (blue). Co-expression is seen by double staining and overlays (Merge column).

(B) Quantification of nuclear Nrf2 and cellular 4-HNE immunofluorescence in macrophages (magnification $\times 1200$ ). Box and whiskers plots with median, interquartile range and minimum and maximum values. ${ }^{*} p=10^{-4}$ vs NE groups. Images are representative of all samples. NE-NS and NE-S, patients without emphysema non-smokers and smokers, respectively; SE, patients with severe emphysema.

known to affect different lung regions to a varying extent. However, in pilot experiments we verified the reproducibility of our findings in tissue sampled at different sites from two lungs.

In addition, our groups without emphysema were composed largely of patients with localised carcinoma and, although tissue was sampled at a distance from the carcinomatous lesions, cancer itself may have influenced the results. Nrf2 protein expression has been shown to be increased in cancer tissue, ${ }^{24}$ which may overestimate the differences between patients with and without emphysema. However, in cancer tissue Keap1 protein expression is increased, ${ }^{24}$ a phenomenon not observed in our samples.

Another potential bias of this study is related to tobacco consumption, since alveolar macrophage dysfunction in COPD may be attributed to active smoking. ${ }^{37}$ However, although most of our patients with emphysema were ex-smokers, we cannot 
completely rule out an effect of cigarette smoking on our results.

In conclusion, our results showed abnormalities in the expression of Nrf2/Keap1 and Bach1 transcription factors and the ensuing antioxidant phase 2 genes $\mathrm{HO}-1, \mathrm{GPX} 2$ and NOO1 in alveolar macrophages from subjects with smoking-related severe emphysema. These phenomena were associated with an increased oxidative burden. A better understanding of the altered expression of these transcription factors is needed to establish new therapeutic strategies for emphysema and COPD that could be based on preservation and/or restoration of the equilibrium between Nrf2/Keap1 and Bach1.

Acknowledgements: The authors thank Cecile Pouzet, Samira Benadda (IFR 02, Université Paris 7, Faculté de Médecine Denis Diderot-site Bichat, Paris) for confocal analysis expertise.

Funding: Part of this work was supported by grants from Centre d'Assistance Respiratoire à Domicile d'lle de France (CARDIF) and Boehringer-Ingelheim. NA and MB were supported by Chancellerie des Universités de Paris (Legs Poix) and JB by INSERM and Assistance Publique-Hôpitaux de Paris (Contrat d'Interface).

\section{Competing interests: None.}

Ethics approval: This study was approved by the local ethics committee of Saint Germain en Laye hospital (20 rue Amargis, 78100 Saint Germain en Laye, France) and stored biopsies were reported to our institutional board (Délégation à la Recherche Clinique, Assistance Publique-Hôpitaux de Paris, Carré Historique de l'Hôpital SaintLouis, 1 avenue Claude Vellefaux 75010 Paris, France).

\section{REFERENCES}

1. Vestbo J, Hogg JC. Convergence of the epidemiology and pathology of COPD. Thorax 2006:61:86-8.

2. MacNee W. Pathogenesis of chronic obstructive pulmonary disease. Proc Am Thorac Soc 2005;2:258-66; discussion 290-1.

3. Finkelstein R, Fraser RS, Ghezzo $\mathrm{H}$, et al. Alveolar inflammation and its relation to emphysema in smokers. Am J Respir Crit Care Med 1995;152(5 Pt 1):1666-72.

4. Barnes PJ. Alveolar macrophages in chronic obstructive pulmonary disease (COPD). Cell Mol Biol (Noisy-le-grand) 2004;50:0L627-37 (online publication).

5. Fredenburgh LE, Perrella MA, Mitsialis SA. The role of heme oxygenase-1 in pulmonary disease. Am J Respir Cell Mol Biol 2007;36:158-65.

6. Kensler TW, Wakabayashi N, Biswal S. Cell survival responses to environmental stresses via the Keap1-Nrf2-ARE pathway. Annu Rev Pharmacol Toxicol 2007:47:89-116.

7. Ishii Y, Itoh K, Morishima Y, et al. Transcription factor Nrf2 plays a pivotal role in protection against elastase-induced pulmonary inflammation and emphysema. $J$ Immunol 2005; 175:6968-75.

8. Rangasamy T, Cho CY, Thimmulappa RK, et al. Genetic ablation of Nrf2 enhances susceptibility to cigarette smoke-induced emphysema in mice. J Clin Invest 2004; 114:1248-59.

9. Alam J, Cook JL. How many transcription factors does it take to turn on the heme oxygenase-1 gene? Am J Respir Cell Mol Biol 2006;36:166-74.

10. Yamada N, Yamaya M, Okinaga S, et al. Microsatellite polymorphism in the heme oxygenase-1 gene promoter is associated with susceptibility to emphysema. Am J Hum Genet 2000;66:187-95.

11. Guenegou A, Leynaert B, Benessiano J, et al. Association of lung function decline with the heme oxygenase-1 gene promoter microsatellite polymorphism in a general population sample. Results from the European Community Respiratory Health Survey (ECRHS), France. J Med Genet 2006; $43:$ :e43.

12. Maestrelli P, Paska C, Saetta M, et al. Decreased haem oxygenase-1 and increased inducible nitric oxide synthase in the lung of severe COPD patients. Eur Respir J 2003;21:971-6.
13. Slebos DJ, Kerstjens HA, Rutgers SR, et al. Haem oxygenase-1 expression is diminished in alveolar macrophages of patients with COPD. Eur Respir $J$ 2004;23:652-3

14. Stringer KA, Freed BM, Dunn JS, et al. Particulate phase cigarette smoke increases MnSOD, NQ01, and CINC-1 in rat lungs. Free Radic Biol Med 2004;37:1527-33.

15. Singh A, Rangasamy T, Thimmulappa RK, et al. Glutathione peroxidase 2, the major cigarette smoke-inducible isoform of GPX in lungs, is regulated by Nrf2. Am J Respir Cell Mol Biol 2006;35:639-50.

16. Uchida K, Szweda LI, Chae HZ, et al. Immunochemical detection of 4hydroxynonenal protein adducts in oxidized hepatocytes. Proc Natl Acad Sci USA 1993;90:8742-6.

17. Rahman I, van Schadewijk AA, Crowther AJ, et al. 4-Hydroxy-2-nonenal, a specific lipid peroxidation product, is elevated in lungs of patients with chronic obstructive pulmonary disease. Am J Respir Crit Care Med 2002;166:490-5.

18. Bonay M, Boutten A, Lecon-Malas V, et al. Hepatocyte and keratinocyte growth factors and their receptors in human lung emphysema. BMC Pulm Med 2005;5:13.

19. Taille C, Foresti $R$, Lanone $S$, et al. Protective role of heme oxygenases against endotoxin-induced diaphragmatic dysfunction in rats. Am J Respir Crit Care Med 2001;163(3 Pt 1):753-61.

20. Soler D, Chapman TR, Poisson LR, et al. CCR8 expression identifies CD4 memory $T$ cells enriched for FOXP3+ regulatory and Th2 effector lymphocytes. J Immunol 2006;:177:6940-51.

21. Taille C, El-Benna J, Lanone S, et al. Induction of heme oxygenase-1 inhibits NAD(P)H oxidase activity by down-regulating cytochrome b558 expression via the reduction of heme availability. J Biol Chem 2004;279:28681-8.

22. Hovius $\mathbf{R}$, Lambrechts $\mathrm{H}$, Nicolay $\mathrm{K}$, et al. Improved methods to isolate and subfractionate rat liver mitochondria. Lipid composition of the inner and outer membrane. Biochim Biophys Acta 1990;1021:217-26.

23. Maestrelli P, El Messlemani AH, De Fina 0, et al. Increased expression of heme oxygenase (HO)-1 in alveolar spaces and $\mathrm{HO}-2$ in alveolar walls of smokers. Am J Respir Crit Care Med 2001;164(8 Pt 1):1508-13.

24. Stacy DR, Ely K, Massion PP, et al. Increased expression of nuclear factor E2 p45related factor 2 (NRF2) in head and neck squamous cell carcinomas. Head Neck 2006;28:813-8.

25. Papaiahgari S, Zhang Q, Kleeberger SR, et al. Hyperoxia stimulates an Nrf2-ARE transcriptional response via ROS-EGFR-PI3K-Akt/ERK MAP kinase signaling in pulmonary epithelial cells. Antioxid Redox Signal 2006:8:43-52.

26. Warabi E, Takabe W, Minami T, et al. Shear stress stabilizes NF-E2-related factor 2 and induces antioxidant genes in endothelial cells: role of reactive oxygen/nitrogen species. Free Radic Biol Med 2007:42:260-9.

27. Kannan S, Jaiswal AK. Low and high dose UVB regulation of transcription factor NFE2-related factor 2. Cancer Res 2006;66:8421-9.

28. Atzori L, Caramori G, Lim S, et al. Effect of cigarette smoking on haem-oxygenase expression in alveolar macrophages. Respir Med 2004;98:530-5.

29. Maines M. The heme oxygenase system: a regulator of second messenger gases. Annu Rev Pharmacol Toxicol 1997;37:517-54.

30. Converso DP, Taille C, Carreras MC, et al. HO-1 is located in liver mitochondria and modulates mitochondrial heme content and metabolism. FASEB J 2006;20:1236-8.

31. Lin $\mathbf{0}$, Weis $\mathrm{S}$, Yang $\mathrm{G}$, et al. Heme oxygenase-1 protein localizes to the nucleus and activates transcription factors important in oxidative stress. J Biol Chem 2007;282:20621-33.

32. Kim HP, Wang X, Galbiati F, et al. Caveolae compartmentalization of heme oxygenase-1 in endothelial cells. FASEB J 2004;18:1080-9.

33. Nakahira K, Kim HP, Geng XH, et al. Carbon monoxide differentially inhibits TLR signaling pathways by regulating ROS-induced trafficking of TLRs to lipid rafts. J Exp Med 2006;203:2377-89.

34. Desmard M, Amara N, Lanone $\mathrm{S}$, et al. Carbon monoxide reduces the expression and activity of matrix metalloproteinases 1 and 2 in alveolar epithelial cells. Cell Mol Biol (Noisy-le-grand) 2005:51:403-8.

35. Shinohara T, Kaneko T, Nagashima Y, et al. Adenovirus-mediated transfer and overexpression of heme oxygenase 1 cDNA in lungs attenuates elastase-induced pulmonary emphysema in mice. Hum Gene Ther 2005;16:318-27.

36. Talalay P, Fahey JW, Holtzclaw WD, et al. Chemoprotection against cancer by phase 2 enzyme induction. Toxicol Lett 1995;82-83:173-9.

37. Woodruff PG, Koth LL, Yang YH, et al. A distinctive alveolar macrophage activation state induced by cigarette smoking. Am J Respir Crit Care Med 2005;172:1383-92. 